managing teams, planning and scheduling, budgeting and performance, and communication and review. As the organization of chapters suggests, in addition to technical skills and a modicum of subject expertise, project managers possess considerable soft skills. In her conclusion, Note observes with characteristic concision that "project managers bring chaos to order and blurred vision to clear reality." (167)

A book whose primary goals are summary and translation of project management methodologies from industry to memory institutions, Project Management for Information Professionals squarely achieves its objectives. Terms often expressed as acronyms in the business world (IRR, SMART, MoSCoW) are spelled out literally and conceptually (internal rate of return; specific, measurable, accurate, realistic, and timebound; must, should, could, will not). A thorough glossary also helps readers to grasp and retain unfamiliar terminology.

Clearly delineated contrasts also aid the work of translating project management into a cultural heritage context. Whereas in the for-profit world, project managers are known by that title, in LAMs many people lead projects that draw on their expertise but take place outside of their daily responsibilities-for example, a director of technical services leading a task force to identify and implement a new ILS. Another common difference between project management in the business world and in the cultural heritage world is a project's motivation: rather than generating revenue, the purpose of project in a library, archive, or museum is more likely to be improving services or reducing costs, outcomes that require different metrics to demonstrate. Note deftly draws these distinctions while underscoring the applicability of project management techniques to industry and cultural heritage, large and small projects alike.

The book does not necessitate linear reading to derive value from the reading experience. Each chapter is preceded by apt epigrams ranging from lyric to comic. For example, Chapter 6 on "Communication and Documentation," opens with the observations that "much unhappiness has come into the world becomes of bewilderment and things left unsaid" (Dostoevsky) and that "The single biggest problem in communication is the illusion that it has taken place" (George Bernard Shaw). These delightful epigrams invite readers to follow their curiosity, finding a starting place wherever their attention is captured. By the same token, trenchant figures that summarize crucial concepts, and appendixes that articulate key questions and provide document templates, facilitate quick reference in the midst of a project.

Throughout, project management concepts or techniques are often illustrated using a LAM example. For instance, Note points to installing shelving before shifting collections as an example of a mandatory dependency (81). However, these illustrations tend to be parenthetical.

More vivid, in-depth explorations of project management principles at work in LAM contexts would bolster her case that individuals and organizations ought to adopt a project management approach. For example, in addition to enumerating elicitation techniques, Section 2.4 on "Gathering Requirements" might also have provided sample responses to structured stakeholder interviews, drawn from Note's extensive experience, and paired these responses with a discussion of how what was elicited reframed project goals and better positioned the project to succeed. Without impact stories punctuating deep summary of project management methodologies, even the crispest prose becomes difficult to penetrate, except to search for the answer to a specific question.

Though dry on occasion, as a whole Project Management for Information Professionals is clearly envisioned and executed as a handbook for librarians, archivists, and curators who find themselves leading project-based work. By empowering individual information professionals to manage projects more effectively, this work may play a part in shifting the organizational culture of memory institutions: from taking a defensive stance within an information environment in constant flux, to embracing project-based work as a way for libraries, archives, and museums to learn and grow and vitally engage the communities they serve.

Note is the consummate project manager, and it shows in her handbook of project management for information professionals. This book knows what it is, and what it is not; it remains true to its project scope. It achieves its objectives, and delivers what it promises to its readers. Novice project managers will keep it close at hand; more experienced project managers will consult it when they feel themselves becoming stuck and will look back at past projects with a sharper eye for what they might do better.-Chelcie Juliet Rowell (rowellcj@wfu.edu),Wake Forest University,Winston-Salem, North Carolina

\section{Maximizing Electronic Resources Management in Libraries: Applying Business Process Management.} By Lenore A. England and Stephen D. Miller. Amsterdam: Chandos, 2016. 139p. $\$ 68.00$ softcover (ISBN 978-1-84334747-7); \$68.00 e-book (ISBN 978-1-78063-428-9).

One of the themes emphasized throughout Maximizing Electronic Resources Management in Libraries is that Electronic Resource Management (ERM) is a form of knowledge work that is complex, patchworked and often does not lend itself to routine. Expertise in the subject is gained over time and through the experience of grappling with different issues and solving a variety of problems. The other theme is effective organization of electronic resources is critical to the success of libraries and to the institutions of which they are a part $(1,9)$.

These concepts may not seem like breaking news, but it is nice to see them in print—clear and unambiguous. More 
importantly, the concepts are easy to remember the next time one encounters a person who believes that everything on the Internet is free, credible, and easy to find. Or an administrator who does not understand why library costs are ever increasing when there is so much free stuff available for the taking, no work needed. Maybe in reply to the question, "What does an E-Resources Librarian do?" this reviewer will channel the words of England and Miller. Both have established records of scholarship and creative leadership in ERM and related subjects. England received the 2012 Association of Library Collections and Technical Services/ Collection Management Section Coutts Award for Innovation in ERM.

The authors describe their initial situation as that of a small staff struggling with an overload of work at the University of Maryland University College (UMUC) and with a need to manage it before it became overwhelming. Determined to develop a system focused on users' needs, they began to distill down the best of the proven management theories to use with ERM work, and ultimately chose to apply business process management (BPM) principles. The authors both come from a business management background and each holds an MBA degree and an MS in Library Science. This background is likely what influenced them to consider applying management theories to ERM in libraries and to then offer that idea to libraries of all types and sizes.

The book begins with a brief overview of ERM and what it does. The discussion of ERM as a form of knowledge work that is vital to the infrastructure of libraries and institutions is expanded upon. Care is taken to not only provide an operational point of view, but also the perspective of library users with continuously evolving expectations. However, the focus of the book is not on the various ERM systems that are available and are likely to be set up differently for each library, but on the organizational tools that BPM can offer. The idea is to think outside of ERM systems to provide what the user wants: simple access to needed information sources in a way that is familiar and functional.

The authors explain that workflow analysis is a critical component of BPM. England and Miller emphasize that organization is critical to successful ERM. Within the constantly changing environment for electronic resources, lack of an organized structure may cause staff to replicate work, develop strategies that do not coordinate efficiently and unintentionally create workflow silos that suppress creativity and innovative thinking. Organizational changes will affect areas such as collection development, acquisitions, training needs and technical requirements, so it is important to maintain a wide view when examining workflows and implementing changes (23). In addition to structural analysis and reorganization, mapping ERM personnel, systems, and tools to the organizational structure provides an understanding of where staff and tools are distributed in the workflow process: who is responsible for each functional area and what tools are utilized (24). The text includes graphics that illustrate the distinct components and issues of ERM, as well as a clear example of mapping an ERM organizational structure to related workflows.

The authors then discuss the history and evolution of BPM and the various management theories of the nineteenth and twentieth centuries. At this point the reader might be tempted to skip ahead, but fear not. The review is interesting; traveling from the Efficiency Movement of the late 1800s, stopping off at Henry Ford's system of assembly line Mass Production, and then briefly examining how the contributions of W. Edwards Deming, the Japanese Production System, TQM, Lean Production and Six Sigma led to the development of BPM as a discipline. The authors stress that it is "important to understand the background and development of these systems as they relate to developing and improving the quality of business processes in order to better achieve organizational goals. BPM and improvement is ... fundamentally intertwined and critical to all each [sic] of these management methods" (42-43). The overview of management theories gives a sense of history and context to the reader and makes it clear that England and Miller have built their "approach to the application of BPM to ERM on the shoulders of the giants of management theories and principles" (7).

Chapter 5 provides an overview of the use of BPM within libraries in general before specifically discussing the application of BPM to ERM. The authors assert that although examples of applying BPM to other areas of library work exist, the actual practice of applying BPM to ERM itself has not previously been done. Detailed descriptions and images are provided to explain the stages (define, measure, analyze, improve, and control) of the BPM process. England and Miller formulate a plan to extend the management of ERM processes across the university organization to other departments that purchase electronic resources. They describe this as "creating a consortium within the university" (82) and theorize that coordinating with other departments will result in a reduction of costs in terms of pricing and maintenance while leveraging the library's expanded knowledge of license agreements and procurement processes and procedures.

Attention is given to the concepts of systems thinking, process mapping, and their implications for ERM. Understanding and accounting for the complex and inter-related processes that constitute ERM, and mapping out each workflow into its constituent parts leads to the ability to visualize the components and the relationships between them. This in turn leads to the ability to further envisage and creatively design future desired outcomes (i.e., greater efficiencies, effectiveness, and flexibility in the face of continuous change). Many techniques for capturing workflows are 
presented and different types of charts and documentation are shown as examples.

The final chapters provide additional BPM approaches that can be applied to ERM and that offer ERM librarians different and innovative ways to think about their work and the processes and systems that they manage. These areas are considered to have potential for future exploration within the field of ERM. Other aspects were discussed and analyzed, such as the financial benefits of applying BPM to ERM, ways in which BPM ideas can be applied to specific ERM processes, and the future of BPM to ERM.

It is obvious that careful consideration was given to providing ERM librarians with a practical skillset and a clear way to apply BPM principles to ERM in a variety of libraries. The book is organized in a methodical manner that allows the reader to move easily from one concept to the next. Each chapter begins with an abstract and keywords, is subdivided into well-defined sections, and ends with extensive references. Regretfully, the book appears to have not received careful copy-editing. Errors and typos occur frequently enough to disrupt the flow of reading and sometimes obscure the authors' intended meaning. While this does not detract from the value of the content, it does affect readability. Despite this drawback, Maximizing Electronic Resources Management in Libraries offers solid ideas for ERM librarians who are looking for a way to organize ERM systems and processes in any size or type of library.-Marie Seymour-Green (seymour@udel.edu),University of Delaware, Newark, Delaware 